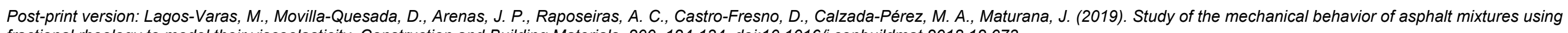
fractional rheology to model their viscoelasticity. Construction and Building Materials, 200, 124-134. doi:10.1016/j.conbuildmat.2018.12.073

\title{
Study of the mechanical behavior of asphalt mixtures using fractional rheology to model their viscoelasticity
}

M. Lagos-Varas ${ }^{\mathrm{a}}$

D. Movilla-Quesada ${ }^{a}$

(c) 2018. This manuscript version is made available under the CC-BY-NC-ND 4.0 license

J.P. Arenas ${ }^{\mathrm{b}}$ http://creativecommons.org/licenses/by-nc-nd/4.0/

A.C. Raposeiras ${ }^{a, *}$

D. Castro-Fresno ${ }^{c}$

M.A. Calzada-Pérez ${ }^{\mathrm{d}}$

A. Vega-Zamanillo ${ }^{d}$

J. Maturana ${ }^{e}$

${ }^{\mathrm{a} G i 2 V}$ Research Group, Institute of Civil Engineering, University Austral of Chile, P.O. Box 567, Valdivia, Chile

Institute of Acoustics, University Austral of Chile, P.O. Box 567, Valdivia, Chile

cGITECO Research Group, Dept. of Transportation and Technology of Projects and Processes, University of Cantabria, 39005 Santander, Spain ${ }^{d}$ Group of Roads (GCS), Dept. of Transportation and Technology of Projects and Processes, University of Cantabria, 39005 Santander, Spain eInstitute of Informatics, University Austral of Chile, P.O. Box 567, Valdivia, Chile

${ }^{*}$ Corresponding author at: Institute of Civil Engineering, University Austral of Chile, P.O. Box 567, Valdivia, Chile. E-mail address: aitor.raposeiras@uach.cl (A.C. Raposeiras).

Abstract

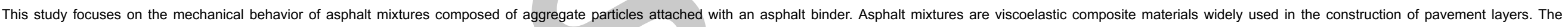

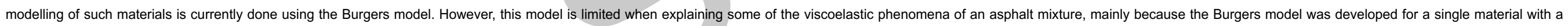

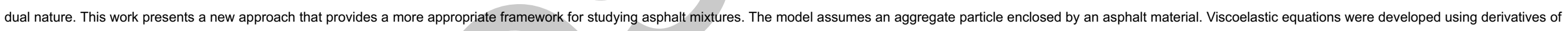

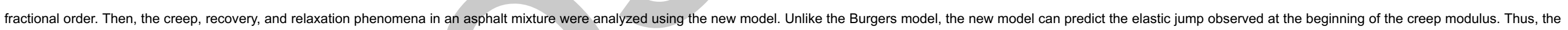

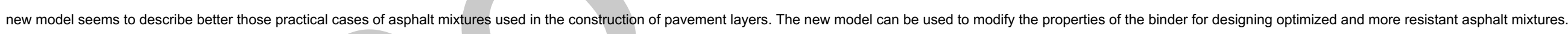

Keywords: Viscoelasticity; Asphalt mixtures; Fractional rheology; Aggregate; Binder

\section{Introduction}

Asphalt mixtures are currently one of the most used composite materials worldwide. Their primary application is constructing pavement layers for roads, airport runways, bike lanes, railway beds, and sidewalks [1,2].

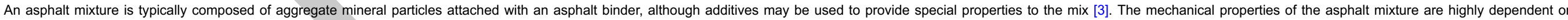
temperature and time of loading [4]. In addition, an asphalt mixture behaves as a viscoelastic material; i.e., it exhibits both viscous-like and elastic characteristics and the relationship between stress and strain depends on time [5,6]. 


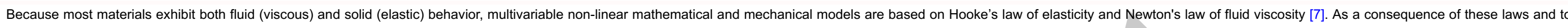

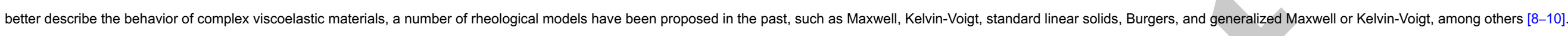

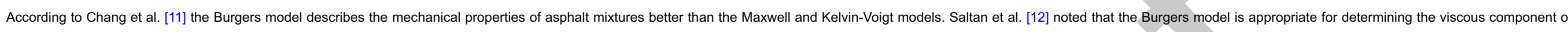

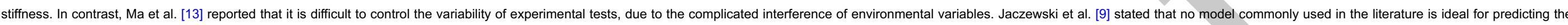

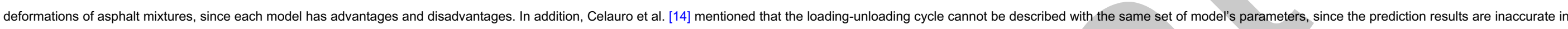
the complete cycle.

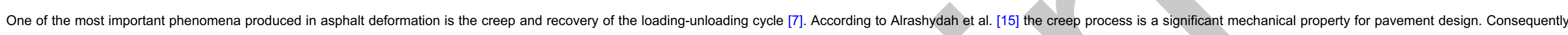

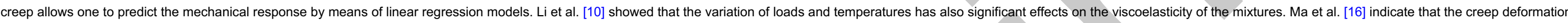

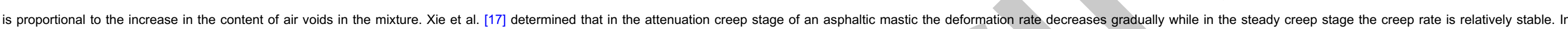

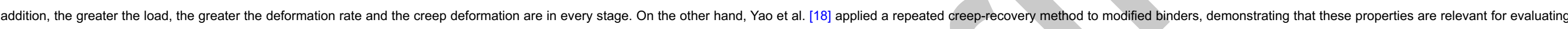

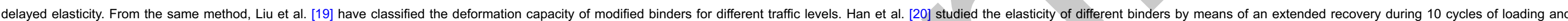
unloading. They concluded that creep deformation and subsequent recovery are important for the design of an asphalt mixture.

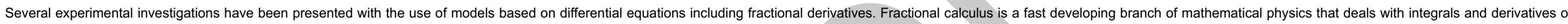

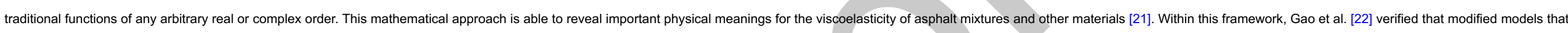

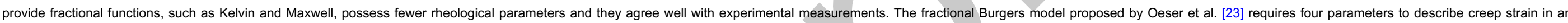

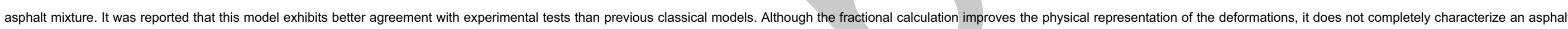

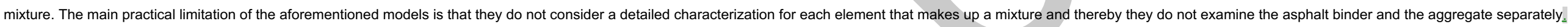

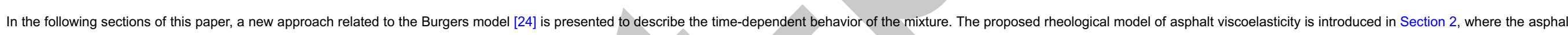

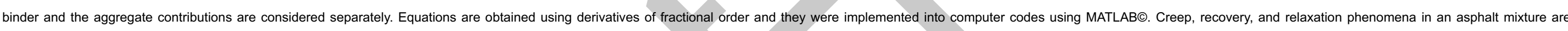
analyzed using the new model and compared with the Burgers model. Results of the experimental validation of the model are presented in Section 3. Finally, the main conclusions are summarized in Section 4.

\section{A rheological model of asphalt viscoelasticity}

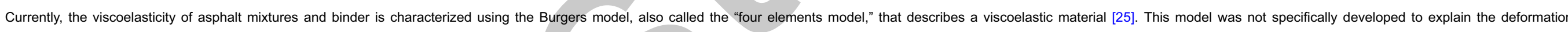

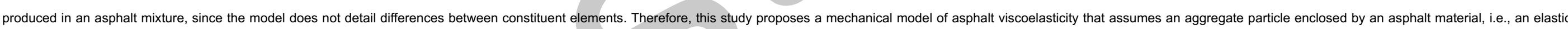
element surrounded by an elastic-viscous set.

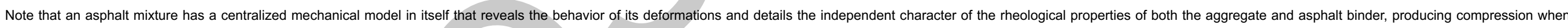
subjected to mechanical tests $[26,27]$.

Fig. 1 shows this relationship from the aggregate characterization, which is represented by the elasticity constant $\xi_{2}$ and the elasticity and viscosity constants representative of the asphalt binder, $\xi_{1}$ and $\eta$, respectively.

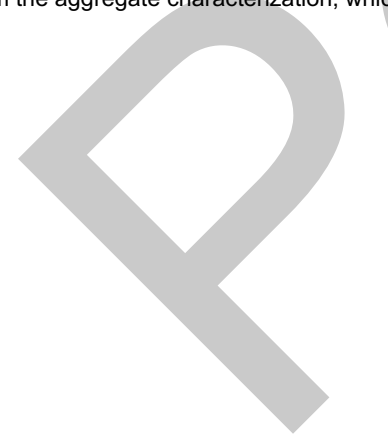




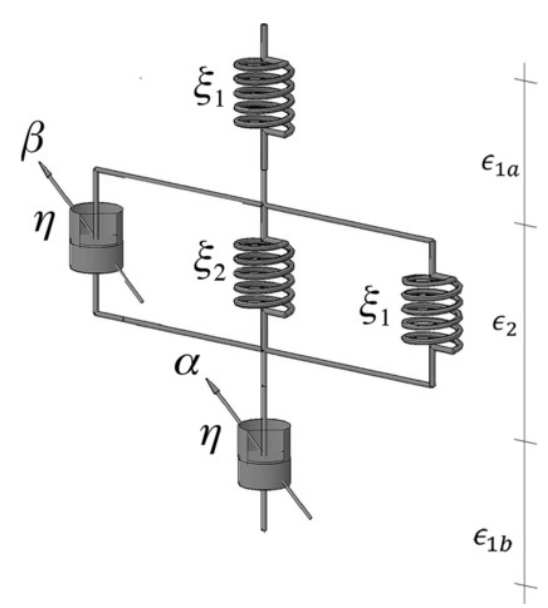

Fig. 1 Schematic diagram of the proposed model of asphalt mixture

The fractional differential equation that governs the previous model was obtained by analyzing two strains in series [28], where the first strain was developed with the classic Maxwell model [29]:

$D_{t}^{\alpha} \epsilon_{1 a+1 b}(t)=\frac{1}{\xi_{1}} D_{t}^{\gamma} \sigma(t)+\frac{1}{\eta} \sigma(t)$,

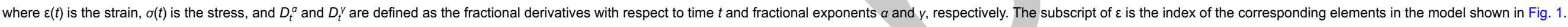

The second strain differs from the Kelvin-Voigt model [30], since it has two purely elastic springs and a viscous damper connected in parallel to consider in more detail the elasticities of an asphalt mixture:

$D_{t}^{\beta} \epsilon_{2}(t)=\frac{1}{\eta} \sigma(t)-\frac{\left(\xi_{1}+\xi_{2}\right)}{\eta} \epsilon_{2}(t)$,

where $\beta$ is also a fractional exponent.

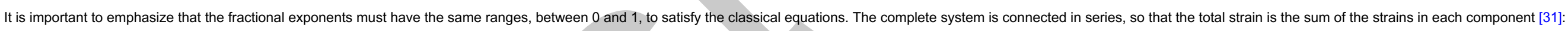
$\epsilon=\epsilon_{1 a}+\epsilon_{2}+\epsilon_{1 b}$

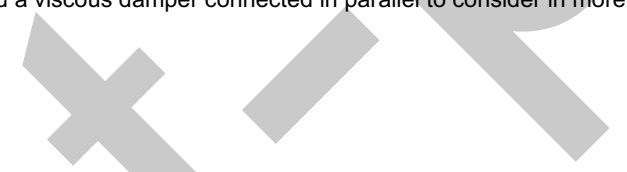

(2)

After substituting the equations and transforming the derivatives in an algebraic form, the differential equation of the proposed asphalt mixture viscoelastic model is (see Appendix A):

$D_{t}^{\alpha+\beta} \epsilon+\frac{\left(\xi_{1}+\xi_{2}\right)}{\eta} D_{t}^{\alpha} \epsilon=\frac{1}{\xi_{1}} D_{t}^{\beta+\gamma} \sigma+\frac{1}{\eta} D_{t}^{\beta} \sigma+\frac{1}{\eta} D_{t}^{\alpha} \sigma+\frac{\left(\xi_{1}+\xi_{2}\right)}{\xi_{1} \eta} D_{t}^{\gamma} \sigma+\frac{\left(\xi_{1}+\xi_{2}\right)}{\eta^{2}} \sigma$.

Applying the Laplace transform to Eq. (4) and assuming zero initial conditions yields the following stress-strain constitutive equation:

$\hat{\epsilon}(s)\left[s^{\alpha+\beta}+\frac{M}{\eta} s^{\alpha}\right]=\hat{\sigma}(s)\left[\frac{1}{\xi_{1}} s^{\gamma+\beta}+\frac{1}{\eta} s^{\beta}+\frac{1}{\eta} s^{\alpha}+\frac{M}{\xi_{1} \eta} s^{\gamma}+\frac{M}{\eta^{2}}\right]$,

where $M=\xi_{1}+\xi_{2}$.

\subsection{Creep phenomenon}

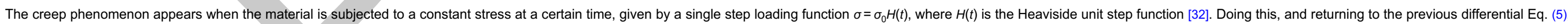
gives [33]:

$\widehat{\epsilon}(s)=\left[\frac{s^{\gamma-\alpha}}{\xi_{1}}+\frac{s^{-\alpha}}{\eta}+\frac{1}{\eta\left(s^{\beta}+\frac{\mathrm{M}}{\eta}\right)}\right] \frac{\sigma_{0}}{s}$. 
$F(t)=\frac{1}{\xi_{1}}+\frac{1}{\eta} \frac{t^{\alpha}}{\Gamma(\alpha+1)}+\frac{1}{\eta} t^{\beta} \sum_{k=0}^{\infty} \frac{\left(-\frac{\mathrm{M}}{\eta} t^{\beta}\right)^{k}}{\Gamma(\beta+1+\beta k)}$,

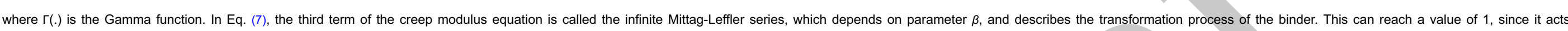
at the same time as elasticity [37].

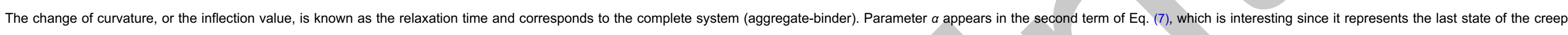

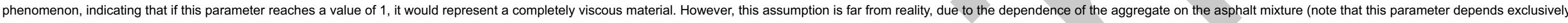

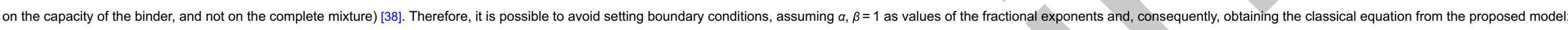

$F(t)=\frac{1}{\xi_{1}}+\frac{t}{\eta}+\frac{1}{M}\left[1-e^{-\frac{M}{\eta} t}\right]$.

We can compare Eq. (8) with the Burgers model, where the classic creep equation is given by the following mathematical expression [39]:

$F_{\text {burgers }}(t)=\frac{1}{\xi}+\frac{t}{\eta}+\frac{1}{\xi}\left[1-e^{-\frac{\xi}{\eta} t}\right]$

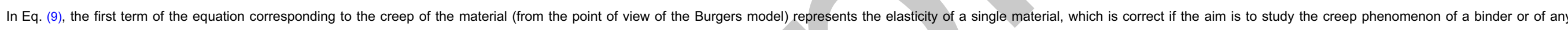

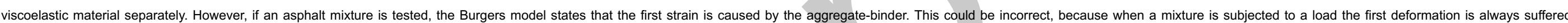
exclusively by the binder, since this a softer material.

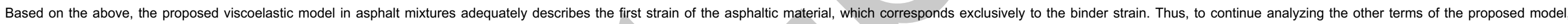
numerical examples are given in the following subsections to compare the effect caused by the fractional parameters $\alpha$ and $\beta$.

\subsubsection{Fractional parameter $\beta$}

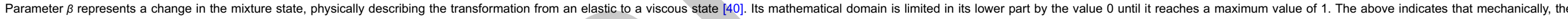

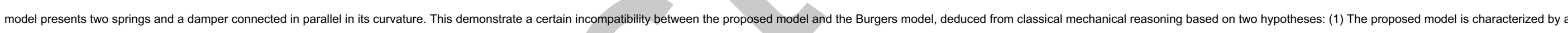
change in the viscoelastic curvature, considering the second elastic jump of the entire asphalt mixture; (2) The space and time dependent model requires fractional calculus.

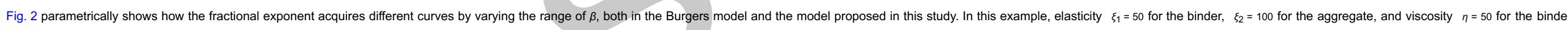
were used. These values have merely been chosen in this example to illustrate more clearly the differences between the Burgers model and the proposed approach.
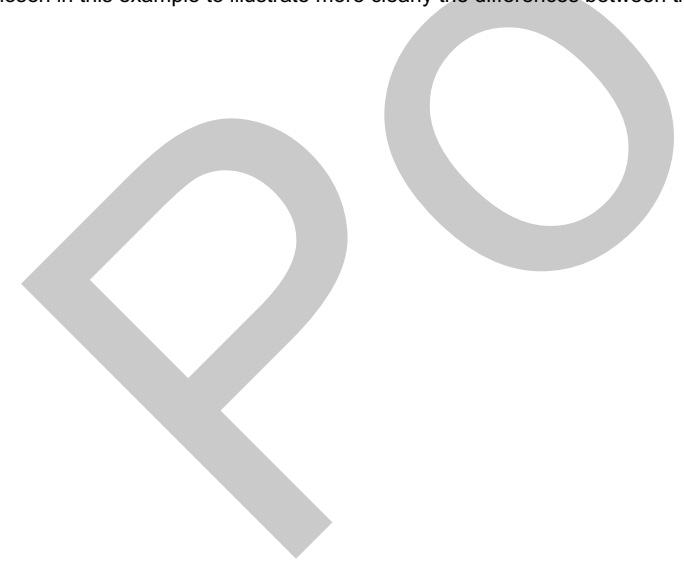


$$
e^{e^{e^{2}}}
$$




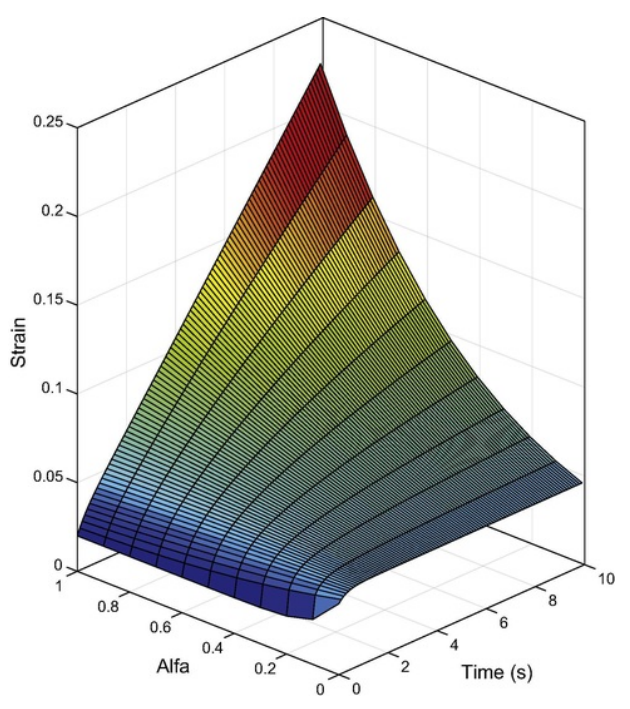

Fig. 3 Results of strain as a function of both time and $\alpha$ for the proposed model with $\beta=1$.

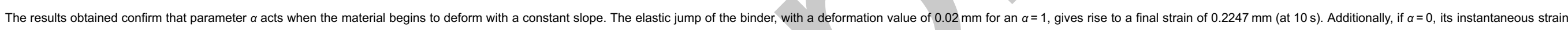

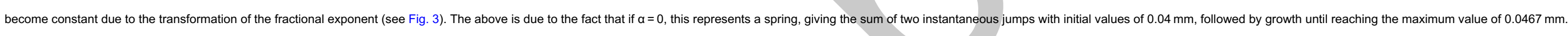

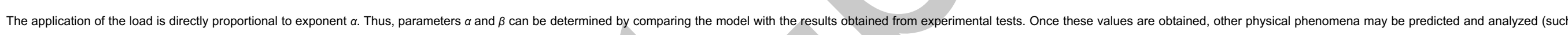
as the dynamic module and/or relaxation test). The importance of this model lays in that we may design an asphalt mixture with a modified binder, so we can build an optimized and more resistant pavement layer.

\subsection{Recovery phenomenon}

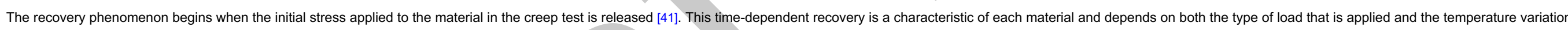
to which the material sample is subjected [42].

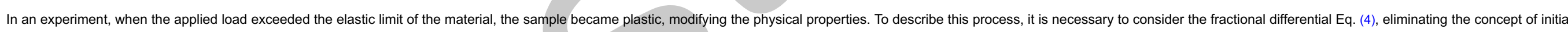

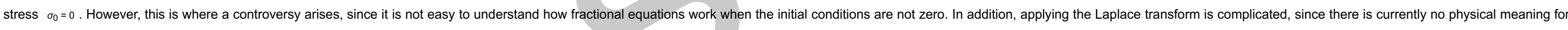
these initial conditions. Therefore, the right-hand side of Eq. (4) is zero. After applying the Laplace transform, Eq. (4) becomes:

$\widehat{\epsilon}(s)\left[s^{\alpha+\beta}-\sum_{k=0}^{m-1} s^{\beta+\alpha-k-1} \epsilon^{k}(0)+\frac{M}{\eta} s^{\alpha}-\sum_{k=0}^{m-1} s^{\beta-k-1} \epsilon^{k}(0)\right]=0$,

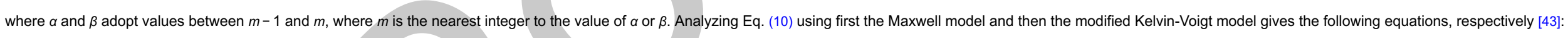

$\hat{\epsilon}(s) s^{\alpha}-\sum_{k=0}^{m-1} s^{\alpha-k-1} \epsilon^{k}(0)=0$,

$\widehat{\epsilon}(s) s^{\beta}-\sum_{k=0}^{m-1} s^{\beta-k-1} \epsilon^{k}(0)+\frac{M}{\eta} \widehat{\epsilon}(s)=0$.

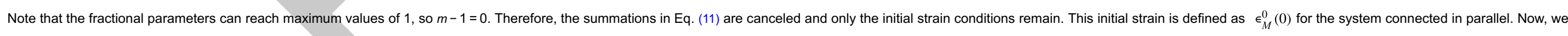
can express the recovery phase of the asphalt viscoelastic model by adding the elastic jump from the Maxwell model, denoted as $\epsilon_{\infty}^{0}(0)$, which gives: 


$$
e^{5} e^{x^{e^{n}}}
$$




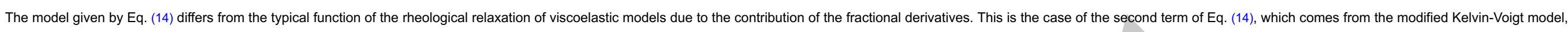
whose fractional parameter is $\beta$ and validates the following relationships:

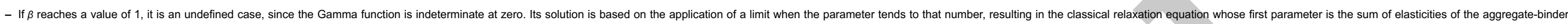
system connected in parallel, plus the Mittag-Leffler function:

$R(t)=M+\xi_{1} \sum_{k=0}^{\infty} \frac{\left(-\frac{\mathrm{M}}{\eta} t^{\alpha}\right)^{k}}{\Gamma(1+\alpha k)}$

- If $\beta$ reaches much lower values (close to 0 ), $\beta$ contributes considerably to the result of the final relaxation function, explaining the viscosity capacity of the binder to dissipate energy. Additionally, note that each value within the established range contributes to the final relaxation modulus.

The proposed model is exclusively linked to the capacity of the binder to release stress. Fig. 5 shows the stress given by the second term in Eq. (14) as a function of both time and $\beta$.

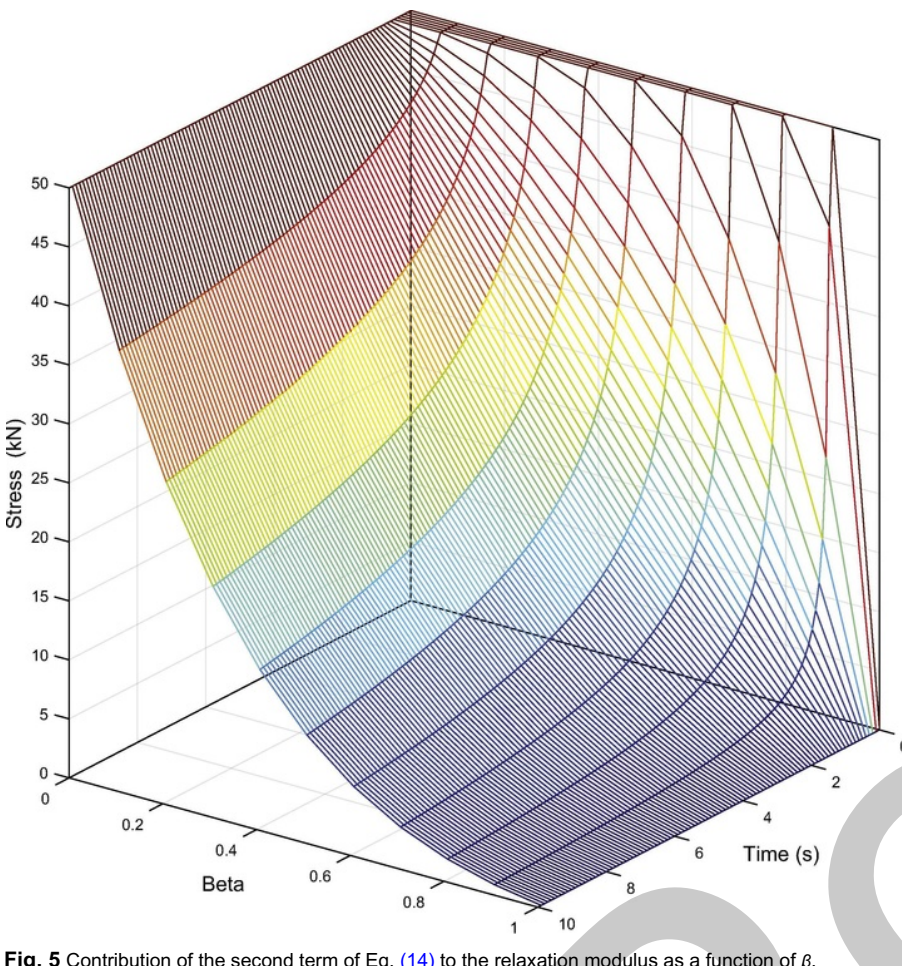

Fig. 5 Contribution of the second term of Eq. (14) to the relaxation modulus as a function of $\beta$.

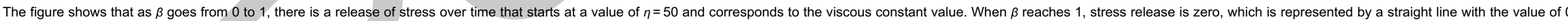
over time, thus confirming the classical model. For values of $\beta<1$, there is residual stress release. This means that knowing the value of $\beta$ associated with each binder is important for real applications.

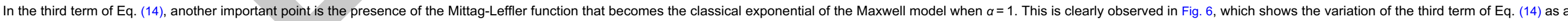
function of both $\alpha$ and time. 

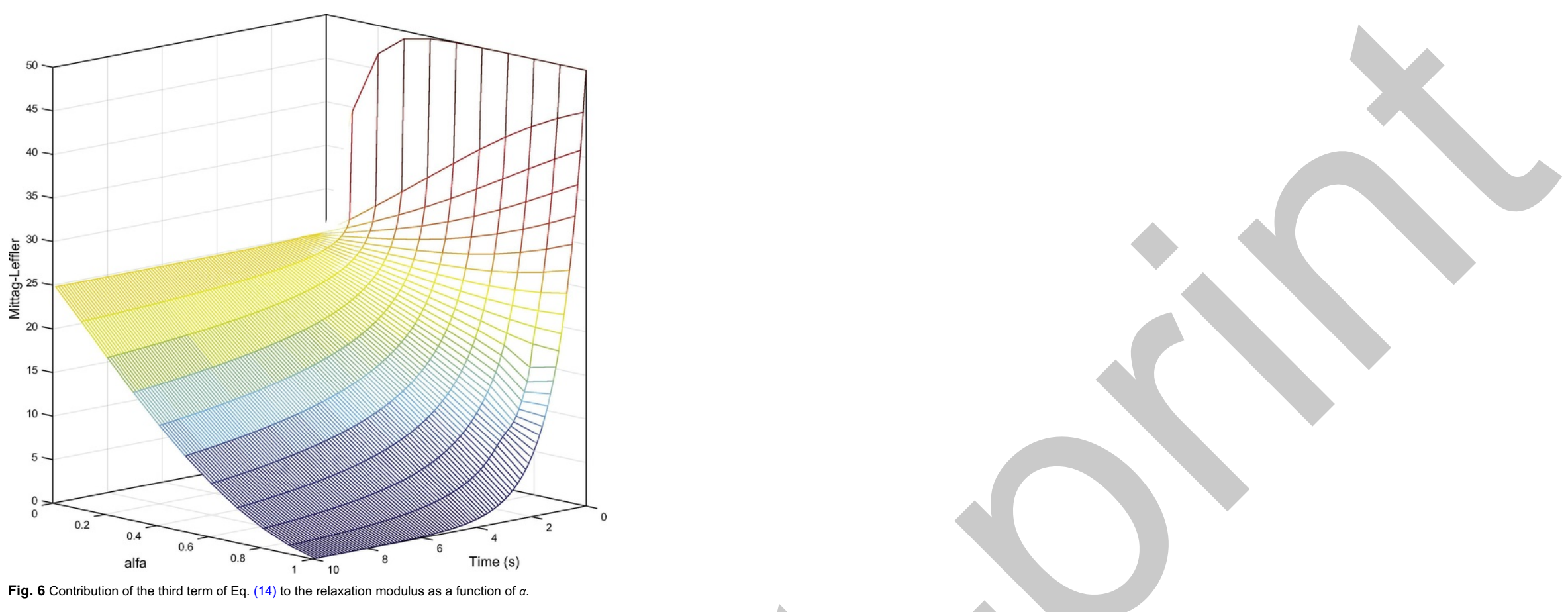

Fig. 6 Contribution of the third term of Eq. (14) to the relaxation modulus as a function of $\alpha$.

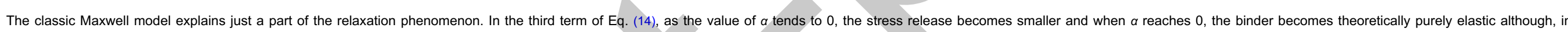
practice, this does not occur. In addition, when $\alpha$ reaches values close to 0.2 , it undergoes a sudden change in relaxation, reaching the linear limit with a value corresponding to half the elastic capacity of the binder.

\section{Experimental verification}

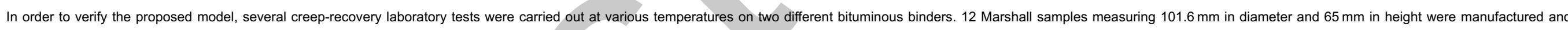

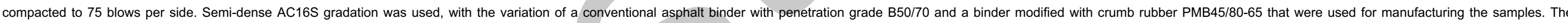
softening points of the conventional and modified binder were $51.6^{\circ} \mathrm{C}$ and $72.3^{\circ} \mathrm{C}$, respectively. Ophitic nature coarse aggregate and limestone nature filler were also employed.

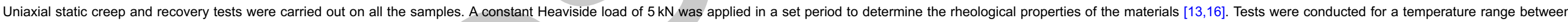
$-10^{\circ} \mathrm{C}$ and $35^{\circ} \mathrm{C}$ (with a scale of $15^{\circ} \mathrm{C}$ )

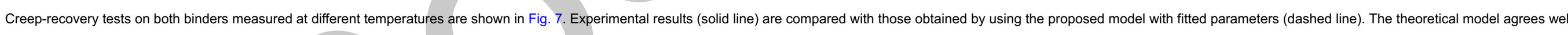

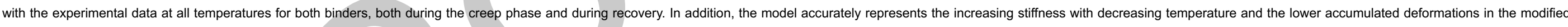
binder compared to the conventional one. The model can show that as the testing temperature increases, a greater viscoelastic deformation occur, each time generating a higher elastic jump and transforming the nonlinear creep. 

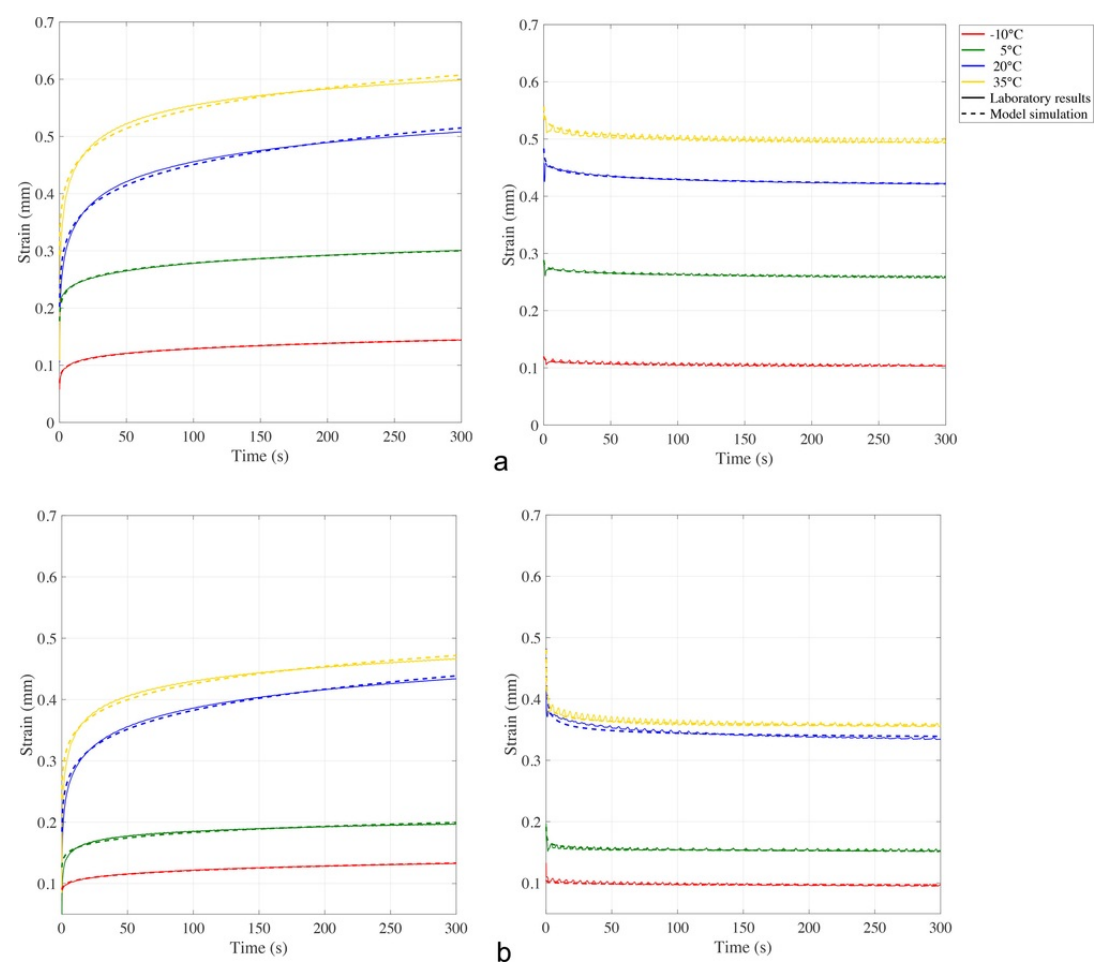

Fig. 7 Creep-recovery tests on binder B 50/70 (a) and PMB 45/80-65 (b). Comparison between experimental data (solid line) and predictions (dashed line) at different temperatures are shown.

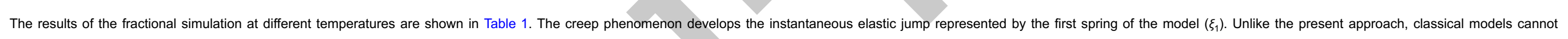

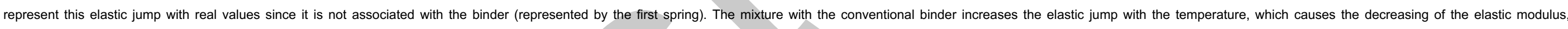

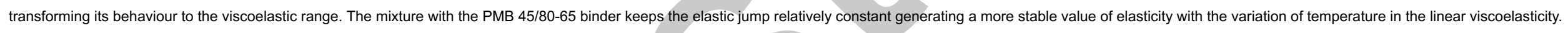

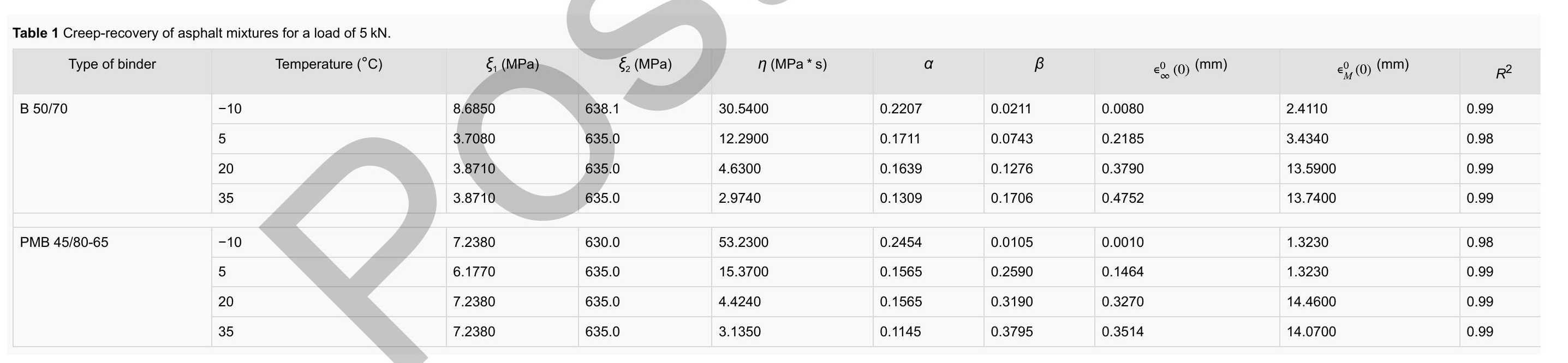




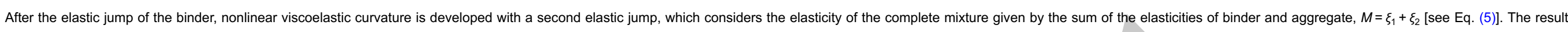

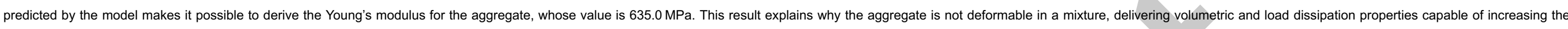

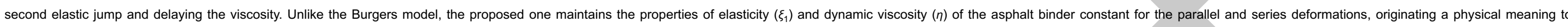

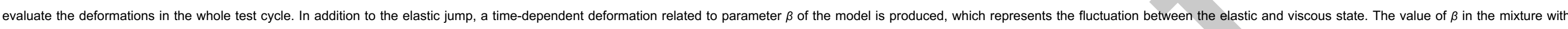
modified binder increases more than that in the mixture with conventional binder, generating more open viscoelastic curves and allowing a recoverable creep.

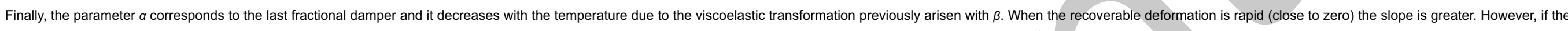

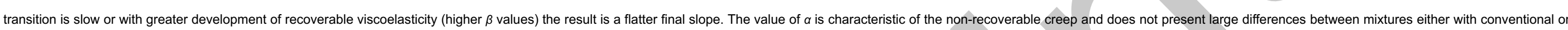
modified binders.

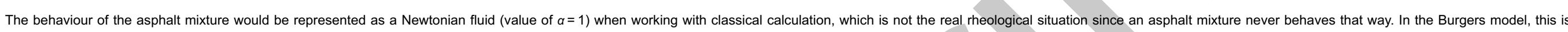

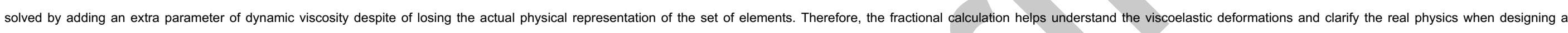
pavement.

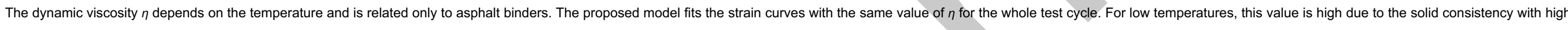

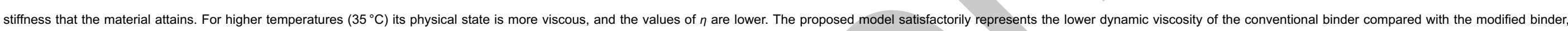
which produces a lower elastic deformation in the asphalt mixture.

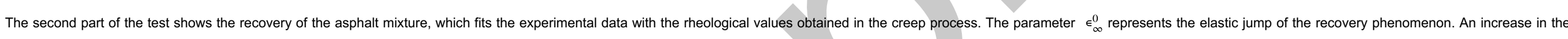

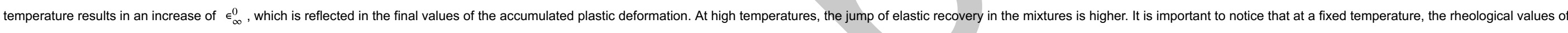

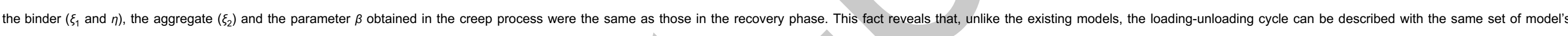

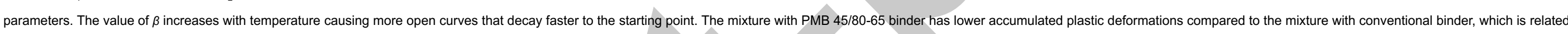
to the increase of $\beta$ by the modified binder. This behaviour allows one to predict the phenomenon of recoverable creep of mixtures.

\section{Conclusions}

From the results of this study, the following conclusions can be made:

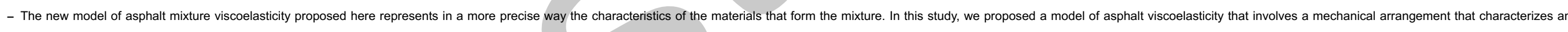

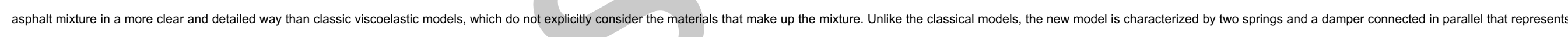
an aggregate particle enclosed by an elastic-viscous binder element. The new model better represents practical cases of asphalt mixtures used in the construction of pavement layers.

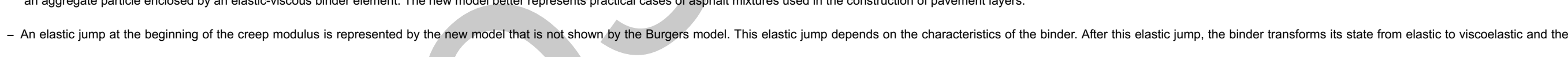
complete mixture acts.

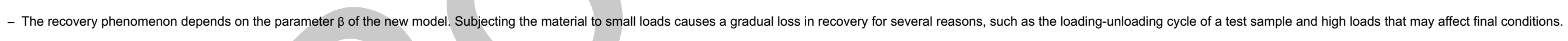

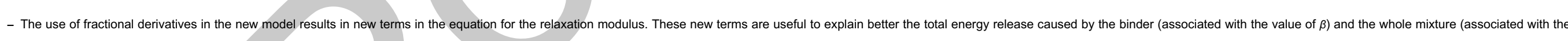
value of $\alpha$ ).

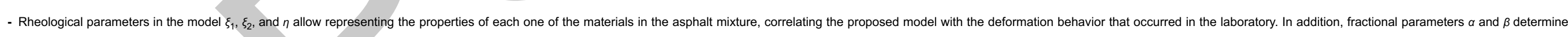
the nonlinear viscoelasticity of asphalt mixtures, detailing the ranges of recoverable and non-recoverable creep for different binders and working temperatures.

- Further work is planned to compare the theory presented in this paper with experimental tests that will include different asphalt mixtures and loading frequencies.

\section{Declarations of interest}


None.

\section{Conflicts of interest statement}

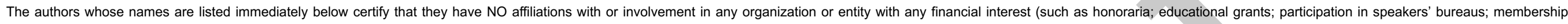

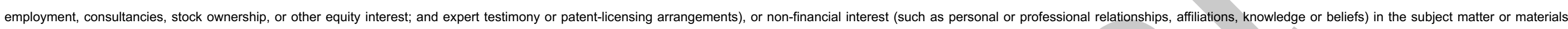
discussed in this manuscript.

\section{Acknowledgments}

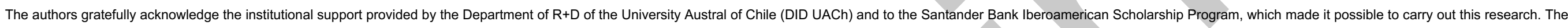
authors would also like to thank the support provided by the GITECO and GCS research groups from the University of Cantabria (Spain).

\section{Appendix A}

The total strain of the system shown in Fig. 1 is given by $\epsilon=\epsilon_{1 a}+\epsilon_{2}+\epsilon_{1 b}$.

The fractional differential equations are given by

$D_{t}^{\alpha} \epsilon_{1 a+1 b}(t)=\frac{1}{\xi_{1}} D_{t}^{\gamma} \sigma(t)+\frac{1}{\eta} \sigma(t)$

and

$D_{t}^{\beta} \epsilon_{2}(t)=\frac{1}{\eta} \sigma(t)-\frac{\left(\xi_{1}+\xi_{2}\right)}{\eta} \epsilon_{2}(t)$.

Taking the fractional derivative of order $\alpha+\beta$ of Eq. (A.1) with respect of time yields $D_{t}^{\alpha+\beta} \in(t)=D_{t}^{\alpha+\beta} \epsilon_{1 a+1 b}+D_{t}^{\alpha+\beta} \epsilon_{2}$.

Now, by taking the fractional derivative of order $\beta$ of Eq. (A.2) and that of order $\alpha$ of Eq. (A.3), we get $D_{t}^{\alpha+\beta} \epsilon_{1 a+1 b}(t)=\frac{1}{\xi_{1}} D_{t}^{\gamma+\beta} \sigma(t)+\frac{1}{\eta} D_{t}^{\beta} \sigma(t)$

and

$D_{t}^{\alpha+\beta} \epsilon_{2}(t)=\frac{1}{\eta} D_{t}^{\alpha} \sigma(t)-\frac{\left(\xi_{1}+\xi_{2}\right)}{\eta} D_{t}^{\alpha} \epsilon_{2}$

Substituting Eqs. (A.5) and (A.6) into Eq. (A.4) gives

$D_{t}^{\alpha+\beta} \in(t)=\frac{1}{\xi_{1}} D_{t}^{\gamma+\beta} \sigma(t)+\frac{1}{\eta} D_{t}^{\beta} \sigma(t)+\frac{1}{\eta} D_{t}^{\alpha} \sigma(t)-\frac{\left(\xi_{1}+\xi_{2}\right)}{\eta} D_{t}^{\alpha} \epsilon_{2}$.

In order to express the fractional differential Eq. (A.7) as a function of the total strain $\varepsilon$ only, we take the fractional derivative of order $\alpha$ of Eq. (A.1) with respect of time $D_{t}^{\alpha} \epsilon=D_{t}^{\alpha} \epsilon_{1 a+1 b}+D_{t}^{\alpha} \epsilon_{2}$

Solving for $D_{t}^{\alpha} \epsilon_{2}$ in Eq. (A.8) and using Eq. (A.2) one obtains the following equation $D_{t}^{\alpha} \epsilon_{2}=D_{t}^{\alpha} \in-\frac{1}{\xi_{1}} D_{t}^{\gamma} \sigma(t)-\frac{1}{\eta} \sigma(t)$.

Now, substituting Eq. (A.9) into Eq. (A.7) gives 


$$
D_{t}^{\alpha+\beta} \in(t)=\frac{1}{\xi_{1}} D_{t}^{\gamma+\beta} \sigma(t)+\frac{1}{\eta} D_{t}^{\beta} \sigma(t)+\frac{1}{\eta} D_{t}^{\alpha} \sigma(t)-\frac{\left(\xi_{1}+\xi_{2}\right)}{\eta}\left(D_{t}^{\alpha} \in-\frac{1}{\xi_{1}} D_{t}^{\gamma} \sigma(t)-\frac{1}{\eta} \sigma(t)\right)
$$

After arranging terms, Eq. (A.10) is expressed as

$$
D_{t}^{\alpha+\beta} \in+\frac{\left(\xi_{1}+\xi_{2}\right)}{\eta} D_{t}^{\alpha} \epsilon=\frac{1}{\xi_{1}} D_{t}^{\beta+\gamma} \sigma+\frac{1}{\eta} D_{t}^{\beta} \sigma+\frac{1}{\eta} D_{t}^{\alpha} \sigma+\frac{\left(\xi_{1}+\xi_{2}\right)}{\xi_{1} \eta} D_{t}^{\gamma} \sigma+\frac{\left(\xi_{1}+\xi_{2}\right)}{\eta^{2}} \sigma,
$$

where the time variable is not explicitly shown for notational simplicity

\section{References}

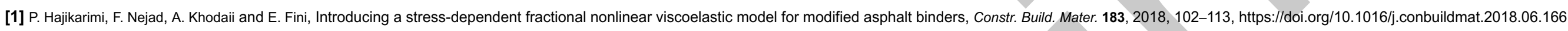
[2] F. Xiao, S. Yao, J. Wang, X. Li and S. Amirkhanian, A literature review on cold recycling technology of asphalt pavement, Constr. Build. Mater. 180, 2018, 579-604, https://doi.org/10.1016/j.conbuildmat.2018.06.006.

[3] M. Zaumanis, L.D. Poulikakos and M.N. Partl, Performance-based design of asphalt mixtures and review of key parameters, Mater. Des. 141, 2018, 185-201, https://doi.org/10.1016/j.matdes.2017.12.035.

[4] J. Chen, T. Wang and C. Lee, Evaluation of a highly-modified asphalt binder for field performance, Constr. Build. Mater. 171, 2018, 539-545, https://doi.org/10.1016/j.conbuildmat.2018.03.188.

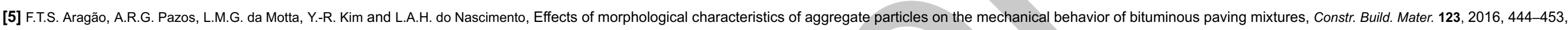
https://doi.org/10.1016/j.conbuildmat.2016.07.013.

[6] F. Moreno, M. Sol, F. Gamiz and M.C. Rubio-Gámez, Mechanical and thermal properties of graphene modified asphalt binders, Constr. Build. Mater. 180, 2018, 265-274, https://doi.org/10.1016/j.conbuildmat.2018.05.259.

[7] C. Fecarotti, C. Celauro and A. Pirrotta, Linear viscoelastic (LVE) behaviour of pure bitumen via fractional model, Procedia Soc. Behav. Sci. 53, 2012, 450-461, https://doi.org/10.1016/j.sbspro.2012.09.896.

[8] Q. Wu, C. Wang, R. Liang, Y. Liu, J. Cheng and Y. Kang, Fractional linear viscoelastic constitutive relations of anhydride-cured thermosetting rubber-like epoxy asphalt binders, Constr. Build. Mater. 170, 2018, 582-590, https://doi.org/10.1016/j.conbuildmat.2018.03.060.

[9] M. Jaczewski, J. Judycki and P. Jaskuła, Modelling of asphalt mixes under long time creep at low temperatures, Transp. Res. Procedia 14, 2016, 3527-3535, https://doi.org/10.1016/j.trpro.2016.05.323.

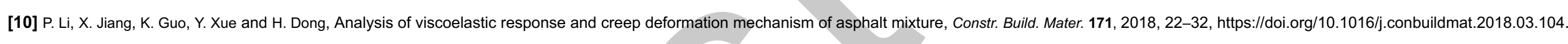

[11] K.-N.G. Chang and J.N. Meegoda, Micromechanical simulation of hot mix asphalt, J. Eng. Mech. 123, 1997, 495-503, https://doi.org/10.1061/(ASCE)0733-9399(1997) 123:5(495).

[12] M. Saltan, S. Terzi and S. Karahancer, Examination of hot mix asphalt and binder performance modified with nano silica, Constr. Build. Mater. 156, 2017, 976-984, https://doi.org/10.1016/j.conbuildmat.2017.09.069.

[13] T. Ma, H. Wang, D. Zhang and Y. Zhang, Heterogeneity effect of mechanical property on creep behavior of asphalt mixture based on micromechanical modeling and virtual creep test, Mech. Mater. 104, 2017, 49-59, https://doi.org/10.1016/j.mechmat.2016.10.003.

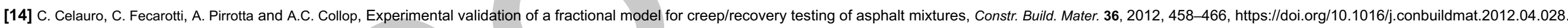

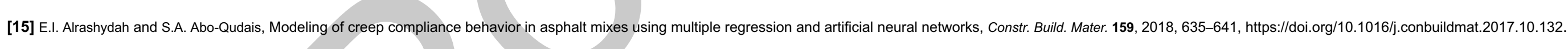

[16] T. Ma, D. Zhang, Y. Zhang, Y. Zhao and X. Huang, Effect of air voids on the high-temperature creep behavior of asphalt mixture based on three-dimensional discrete element modeling, Mater. Des. 89, 2016, 304-313, https://doi.org/10.1016/j.matdes.2015.10.005.

[17] Y.J. Xie, Q. Fu, G.C. Long, K.R. Zheng and H. Song, Creep properties of cement and asphalt mortar, Constr. Build. Mater. 70, 2014, 9-16, https://doi.org/10.1016/j.conbuildmat.2014.07.103.

[18] Z. Yao, J. Zhang, F. Gao, S. Liu and T. Yu, Integrated utilization of recycled crumb rubber and polyethylene for enhancing the performance of modified bitumen, Constr. Build. Mater. 170, 2018, 217-224, https://doi.org/10.1016/j.conbuildmat.2018.03.080.

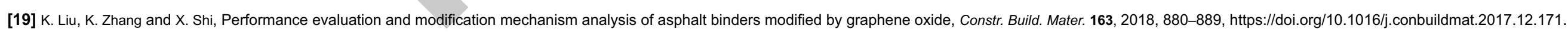


[20] M. Han, J. Li, Y. Muhammad, D. Hou, F. Zhang, Y. Yin and S. Duan, Effect of polystyrene grafted graphene nanoplatelets on the physical and chemical properties of asphalt binder, Constr. Build. Mater. 174, 2018, 108-119, https://doi.org/10.1016/j.conbuildmat.2018.04.082.

[21] A. Loverro, Fractional Calculus: History, Definitions and Applications for the Engineer, 2004, Report Department of Aerospace and Mechanical Engineering, University of Notre Dame; IN.

[22] D. Gao, P. Wang, M. Li and W. Luo, Modelling of nonlinear viscoelastic creep behaviour of hot-mix asphalt, Constr. Build. Mater. 95, 2015, 329-336, https://doi.org/10.1016/j.conbuildmat.2015.07.112.

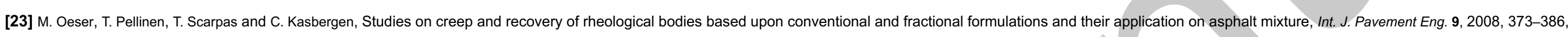
https://doi.org/10.1080/10298430802068923.

[24] X. Qin, S. Zhu, X. He and Y. Jiang, High temperature properties of high viscosity asphalt based on rheological methods, Constr. Build. Mater. 186, 2018, 476-483, https://doi.org/10.1016/j.conbuildmat.2018.07.142.

[25] A.D. Drozdov, Mechanics of Viscoelastic Solids, 1998, Wiley-Interscience; New York.

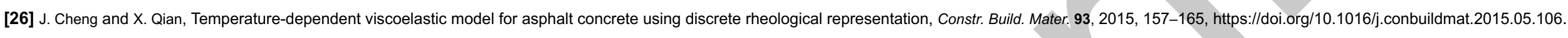

[27] P. Cao, F. Jin, Z. Changjun and D. Feng, Investigation on statistical characteristics of asphalt concrete dynamic moduli with random aggregate distribution model, Constr. Build. Mater. 148, 2017, 723-733, https://doi.org/10.1016/j.conbuildmat.2017.05.012.

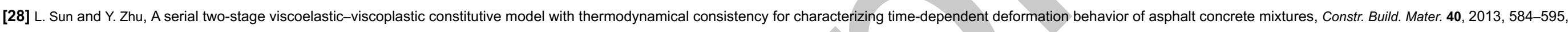
https://doi.org/10.1016/j.conbuildmat.2012.10.004.

[29] Q. You, J. Ma and X. Liu, An experimentally-based viscoelastic behavior of asphalt mastic at high temperatures, Constr. Build. Mater. 177, 2018, 358-365, https://doi.org/10.1016/j.conbuildmat.2018.05.116.

[30] A.D. Mesquita and H.B. Coda, Alternative kelvin viscoelastic procedure for finite elements, Appl. Math. Modell. 26, 2002, 501-516, https://doi.org/10.1016/S0307-904X(01)00048-8.

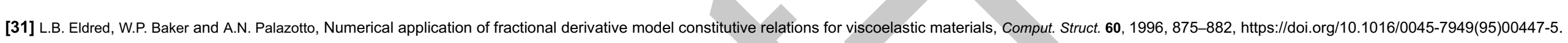

[32] S. Sunarjono, Performance of foamed asphalt under repeated load axial test, Procedia Eng. 54, 2013, 698-710, https://doi.org/10.1016/j.proeng.2013.03.064.

[33] Y. Gao, M. Dong, L. Li, L. Wang and Z. Sun, Interface effects on the creep characteristics of asphalt concrete, Constr. Build. Mater. 96, 2015, 591-598, https://doi.org/10.1016/j.conbuildmat.2015.08.075.

[34] R.M. Christensen, Theory of Viscoelasticity: An Introduction, 1982, Academic Press; New York.

[35] F. Lorenzo and T.T. Hartley, R-Function Relationships in the Fractional Calculus for Application, 2000, National Aeronautics and Space Administration, Glenn Research Center, NASA/TM-2000-210361.

[36] T.T. Hartley and C.F. Lorenzo, A solution to the fundamental linear fractional order differential equation, 1998, National Aeronautics and Space Administration, Lewis Research Center, NASA/TP-1998-208693, December.

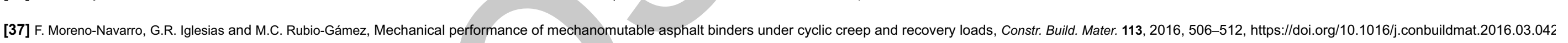

[38] J. Lin, J. Hong and Y. Xiao, Dynamic characteristics of 100\% cold recycled asphalt mixture using asphalt emulsion and cement, J. Clean. Prod. 156, 2017, 337-344, https://doi.org/10.1016/j.jclepro.2017.04.065.

[39] Y.R. Kim, Modeling of Asphalt Concrete, 2007, McGraw Hill; New York.

[40] J. Mandula and T. Olexa, Study of the visco-elastic parameters of asphalt concrete, Procedia Eng. 190, 2017, 7207-7214, https://doi.org/10.1016/j.proeng.2017.05.328.

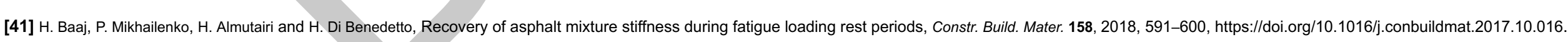

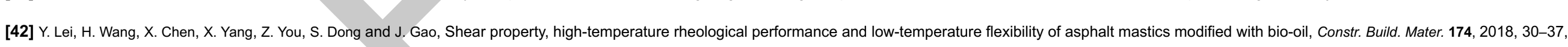
https://doi.org/10.1016/j.cnsns.2018.04.019.

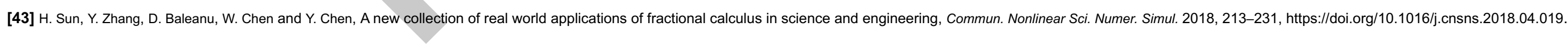




$$
p^{0^{5 e^{2}}}
$$

